\title{
CONCEPCIONES DEL CONFLICTO ARMADO COLOMBIANO EN ESTUDIANTES DE UN CURSO DE SOCIOLOGÍA DE LA UNAD
}

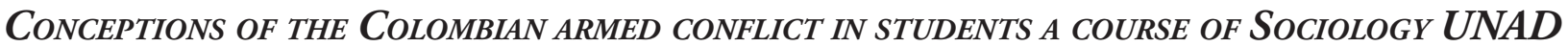

\author{
Hugo Ernesto Perdomo Colina ${ }^{I}$ \\ Universidad Nacional Abierta y a Distancia, UNAD
}

\section{Resumen}

Formar estudiantes integrales donde la proyección social y la capacidad para transformar sus entornos locales, son algunas de las fortalezas que adquieren quienes optan por estudiar en la Universidad Nacional Abierta y a Distancia, UNAD. Este derrotero se convierte en la disculpa académica ideal para que la Escuela de Ciencias Sociales Artes y Humanidades, ECSAH, a través del curso de Sociología, haga de este espacio una experiencia de diálogo social entre el estudiante y esas realidades que circundan nuestro país, en las cuales queramos o no, estamos inmersos e invitados a pensar al país económico, al país social, al país religioso; incluso al país que se sabe al margen de la ley. Es así como el curso de Sociología se convierte en una especie de caldo de cultivo en el cual y a través de temática como la que concierne al I periodo académico 2016: El conflicto armado en Colombia: ¿Un camino hacia el posconflicto?, se le propone al estudiante apoyado en un constructo teórico, abordar esta temática, y a través de la estrategia ABP (Aprendizaje Basado en Problemas), conocer cómo perciben desde sus regiones a ese país al margen de la ley.

De esta manera, el artículo presenta unos resultados preliminares correspondientes al primero de los cuatro momentos de la estrategia didáctica: Clarificación del ámbito y definición del problema.

Palabras clave: conflicto interno, paz, posconflicto, sociología.

\section{Abstract}

Form integral students where social projection and the ability to transform their local environments, are some of the strengths that acquire those who choose to study at the National Open University and Distance, UNAD. This direction becomes the ideal opportunity for the School of Social Sciences, Arts and Humanities, ECSAH, through the course of Sociology, make this space an experience of social dialogue between the student and those realities that surround our country, academic apology which like it or not, we are immersed and invited to think about the country economic, social country, religious country; even the country known outside the law. Thus the sociology course becomes a kind of breeding ground in which and through thematic as regards the I academic period 2016: The armed conflict in Colombia: A path to the post-conflict?, it is proposed the student leaning on a theoretical construct, addressing this subject, and through the PBL (Problem Based Learning) strategy, knowing how they perceive from their regions to that country outside the law.

1 Director nacional del curso de Sociología UNAD, Cead Acacías, Colombia. Sociólogo de la Universidad Nacional, Magister en Intervención Social en las Sociedades del Conocimiento de la Universidad Internacional de la Rioja, UNIR, de Espańa. hugo.perdomo@unad.edu.co. 
In this way, the article presents some preliminary results corresponding to the first of the four stages of the teaching strategy: Clarifying the scope and definition of the problem.

Key Words: internal conflict, peace, post-conflict, sociology.

Recibido: 02 de noviembre de 2015

Aceptado: 30 de noviembre de 2015

\section{Introducción}

La palabra paz, tiene para Colombia una connotación especial; ha sido una de las más repetidas a lo largo de la historia, la cual junto a la infaltable paloma (de la paz) se han constituido para los colombianos y las colombianas en los emblemas más significativos y esperanzadores del fin de un conflicto interno que parecería estaqueado en el tiempo, pero con circunstancias mucho más profundas en la actualidad que aquellas que lo originaron en la década de los años sesentas en la famosa e impenetrable vereda Marquetalia en el departamento del Tolima; en clara alusión a esa etapa fundacional del grupo más representativo y beligerante en el conflicto armado nacional, las Fuerzas Armadas Revolucionarias de Colombia, FARC.

Los contenidos del curso de Sociología sin pretender hacer un recorrido bélico-histórico del conflicto, y sí, a modo de introducción permiten al estudiante una mirada a ese devenir, aunque general, suman en el entendido que facilitan la comprensión de muchos de los aspectos involucrados en este proceso; lo que permite facilitar la visibilización de sus posturas en relación a cómo perciben el conflicto interno colombiano, aprovechando la multiplicidad de regiones de donde provienen los estudiantes matriculados en la UNAD, y el paso obligado académicamente que deben hacer en este curso de carácter interdisciplinario.

Así, y a través de la propuesta del ABP, Aprendizaje Basado en Problemas, se "busca que el alumno comprenda y profundice adecuadamente en la respuesta a los problemas que se usan para aprender, abordando aspectos de orden filosófico, sociológico, psicológico, histórico, práctico, etc. Todo lo anterior con un enfoque integral. La estructura y el proceso de solución al problema están siempre abiertos, lo cual motiva a un aprendizaje consciente y al trabajo de grupo sistemático en una experiencia colaborativa de aprendizaje (Guevara, 2010, p. 159), además de lo anterior, se espera permear la sensibilidad social de los y las estudiantes y así conocer lo que piensan acerca de un tema que es trasversal a toda una nación.

Inicialmente, y a través de preguntas abiertas, se indagó en los y las estudiantes lo que pensaban, o la manera como concebían el conflicto interno en el país, y a la vez su posible tránsito hacia un estado de posconflicto: miradas de diversa índole, matices variados, concepciones manidas, opiniones exacerbadas, donde el arraigo por ideologías políticas se hacían evidente a través de la misma postura política a la que muchos estudiantes daban por hecho pertenecer: derecha o izquierda; y en esa misma proporción se hacían explícitas también sus concepciones frente a los diálogos de paz en La Habana, las cuales en su mayoría apuntaban en dos direcciones: "de acuerdo o en desacuerdo"; "no sirven para nada, o posiblemente ayuden a lograr la paz"; "es una perdedera de tiempo y plata por parte del gobierno"; "perdón sin olvido, o puede ser una nueva oportunidad para el país...”.

Como característica particular se encontró que los estudiantes donde habitualmente los grupos armados, en este caso las FARC, han hecho presencia histórica pero de donde fueron emplazados a raíz de las políticas uribistas, se muestran como los más renuentes a apoyar una eventual firma de un acuerdo de paz; mientras que quienes están radicados en los medianos y grandes centros urbanos son quienes, pese a algunas objeciones estarían dispuestos a apoyar dichos acuerdos. 
Estas posiciones frente al conflicto no distan de la polarización política que desde hace años anida en los anaqueles del país político, y eran previsibles de que afloraran en este ejercicio, pues la comunidad estudiantil también hace parte de ese país que ha vivido los rigores del conflicto desde diferentes ángulos y en diversas proporciones, producto de quienes desde el poder han izado todo tipo de banderas para inventar sus guerras intestinas; luego no era de extrañar que muchas de las posturas de los estudiantes obedezcan a la reproducción de un país donde sus líderes siguen empotrados en odios viscerales, y retóricas vetustas que cada vez recuerdan más es a aquellos períodos de no grata recordación de la política partidista nacional.

Es así como encontramos que un porcentaje significativo de estudiantes no argumentaran sus opiniones sino que a través de juicios de valor y sesgos conceptuales develaban lo que piensan, sin crítica ni criterio alguno, donde expresiones como: "terroristas que seguirán delinquiendo", "asesinos a sueldo que no merecen oportunidades", "es una lástima que el gobierno invierta en los asesinos del país", "todo seguirá lo mismo en mi departamento, con o sin acuerdo de paz"; etc., para referirse a la contra parte del diálogo en La Habana; afirmaciones que ponen de manifiesto uno de los políticos imperantes en el país. Lo que se evidencia en este caso son afirmaciones enjuiciadoras y encasilladas en una estructura común y mediática en la mayoría de estudiantes.

Claro, pero hay una enorme diferencia que debiera desequilibrar la balanza de opiniones de los estudiantes y sus sesgos, en este caso: la academia está como cimiente en este proceso de formación, y ello debería connotar posiciones más liberales en el sentido estricto de la palabra; se esperaría quizás posturas más argumentadas, menos enjuiciadoras y sí con argumentos de peso donde producto de la formación académica se sintiera menos la injerencia caudillista y mediática tanto de los líderes políticos, como también la de las Industrias Culturales que ejercen a diario los medios masivos de comunicación: radio, prensa y televisión, por medio de su intromisión directa en relación por ejemplo, con el proceso de paz en la cual su función informativa se desdibuja en las fronteras de una polarización nacional: ejemplo de ello es la banalización a la que han sido sometidos los diálogos de La Habana, lo que puede ser entendido si "empezamos a comprender que los medios, y las tecnologías de la comunicación en general, atraviesan lo social, atraviesan los imaginarios, atraviesan las percepción, más allá del tiempo en que está expuesto físicamente a ellos, pues operan por articulación de unas con otras, operan en red, cargando-recargando la capacidad de incidir sobre los modos de pensar, de representar la sociedad, de representarnos el cambio, etc. (Barbero, 1995, p. 150).

De igual manera en este primer ejercicio se encontraron incluso miradas al proceso, y al conflicto que evidencian otro tipo de pensamiento el cual podrían denominarse de "centro", es decir estudiantes que conciben la paz no solo como el fin del conflicto armado a través de la firma de los acuerdos de paz en La Habana, sino también como la oportunidad para que un Estado que ha permanecido de espalda a la periferia, y sí con su mirada hacia los grandes centros poblados del país volque su ojos y su presencia, y de la mano de la implementación y ejecución de Políticas Públicas expíe culpas de abandono, en pro del resarcimiento de derechos de ese otro país también llamado Colombia.

Si en la década de los cincuentas del pasado siglo la simbología imperante de los partidos políticos hegemónicos eran los colores azul y rojo, en la actualidad, o se es de derecha o de izquierda; o lo que es similar, connotan a un país de buenos o de malos, desconociendo así por su inmediatez y demás, a ese otro país que se construye día a día en medio del concepto que estas industrias han coadyuvado a imponer en el colectivo nacional, pues "en Colombia, como en ningún otro país latinoamericano, los medios de comunicación viven de los miedos. Son los miedos de la gente los que han hecho que los medios, especialmente la radio y la televisión, ocupen un lugar tan decisivo en la sociedad" (Barbero, 1995, p. 167). 
Por tanto, y siguiendo la senda trazada por quien le dio origen al proyecto educativo unadista, el Dr. Miguel Antonio Ramón Martínez (2007), el curso de Sociología busca desarrollar en los y las estudiantes sensibilidad frente a las problemáticas del mundo que les rodea, con el fin de permitir su comprensión y a la vez posibilitar a través del constructo teórico, un cambio social a su entorno reconociendo la necesidad de transformar las prácticas sociales, los comportamientos personales y las actitudes, para asumir crítica y creativamente los retos y desafíos de la sociedad del conocimiento y del mundo globalizado.

Finalmente y a manera de conclusión, es procedente recordar a través del siguiente párrafo una alusión hecha por el maestro Estanislao Zuleta (2005) a algunos valores que resultan fundamentales para hacer tránsito pacífico en comunidad: "Un síntoma inequívoco de la dominación de las ideologías proféticas y de los grupos que las generan o que someten a su lógica doctrinas que les fueron extrańas en su origen, es el descrédito en que cae el concepto de respeto. No se quiere saber nada del respeto, ni de la reciprocidad, ni de la vigencia de normas universales. Estos valores aparecen más bien como males menores propios de un resignado escepticismo, como signos de que se ha abdicado a las más caras esperanzas. Porque el respeto y las normas sólo adquieren vigencia allí donde el amor, el entusiasmo, la entrega total a la gran misión, ya no pueden aspirar a determinar las relaciones humanas (Zuleta, 2005, p.3).

\section{Referencias}

Barbero, J. M. (1995). PRE-TEXTOS: Conversaciones sobre la comunicación y sus contextos. Cali, Colombia: Centro editorial universidad del Valle.

Guevara, M. G. (2010). Aprendizaje basado en problemas como técnica didáctica para la enseñanza del tema de la recursividad. Inter Sedes, XI (20), 142-167.

Ramón Martínez, M. A. (2011). Proyecto académico pedagógico solidario. Versión 3.0. Bogotá, Colombia: Universidad Nacional Abierta y a Distancia (UNAD).

Zuleta, E. (2005). El elogio de la dificultad y otros ensayos. Medellín, Colombia: Hombre nuevo editores y Fundación Estanislao Zuleta. 